\title{
Tonsillar Carcinoma
}

National Cancer Institute

\section{Source}

National Cancer Institute. Tonsillar Carcinoma. NCI Thesaurus. Code C4825.

A carcinoma arising from the tonsilar epithelium. 